\title{
"GEOGRAFANDO" PRÁTICAS JUVENIS QUE (DE)MARCAM A METRÓPOLE: UMA QUESTÃO DE CURRÍCULO ESCOLAR? \\ "Spatializing" youth practices of marking the city: a school curriculum issue?
}

Elisabete Maria Garbin

Ivaine Maria Tonini

\section{RESUMO}

Busca-seproblematizarcomo determinadaspráticasculturais exercidas por sujeitos jovens nas fendas e na pele das cidades podem produzir múltiplos (e provisórios) pertencimentos identitários. São tematizados grafites e pichações que vestem as ruas e paredes de Porto Alegre/ RS e em que medida elas nos fazem refletir sobre "outros" modos de "ser" e "estar" jovem nas metrópoles, "vestidas" com suas marcas, de seus tempos, de seus pensamentos. Tais culturas contribuem para os nomadismos e flutuações, também para a "lugarização" dos espaços, que movimentam uma espécie de rede de relações de toda ordem. Mostrar que os jovens possuem culturas próprias e que estas precisam ser compreendidas pelos professores possibilita maiores significações no ensino. Práticas pedagógicas que enfocam as diversas formas de manifestação juvenil e suas peculiaridades trazem subsídios para que possa haver uma aproximação maior com o mundo dos sujeitos jovens, da escola, bem como o ensino da geografia.

Palavras-chave: Cultura. Identidade. Escola. Práticas juvenis. Lugar.

\section{ABSTRACT}

The aim of this paper is to question how particular cultural practices by young subjects beneath the "skin" of cities can produce multiple (and temporary) identities. We focus on pieces of graffiti and territorial markers in streets and on walls in Porto Alegre (RS), and seek to understand to what extent they act upon "other" juvenile ways of "being" in the cities, dressed in different markers, times, and thoughts. These cultures lead to nomadic ways of life and fluctuations, and "placeness" of spaces, which move a type of web of relations of all kinds. Showing that young people have their own cultures and that teachers have to understand these teenagers enables wider meanings in teaching. Pedagogical practices focusing on diverse forms of juvenile manifestations and their peculiarities help us to get closer to the world of young subjects, their schools, and geography education.

Keywords: Culture. Identities. School. Juvenile practices. Place.

1 Educadora e professora da Faculdade de Educação, Universidade Federal do Rio Grande do Sul. emgarbin@terra.com.br.

2 Geógrafa, educadora e professora da Faculdade de Educação, Universidade Federal do Rio Grande do Sul (UFRGS). ivaine@terra.com.br.

12 Departamento de Currículo e Ensino, Faculdade de Educação, Universidade Federal do Rio Grande do Sul (UFRGS), Campus Centro, Av. Paulo Gama, 110, Prédio 12201. 90046900. Porto Alegre, RS. 
"Geografando" práticas juvenis que (de)marcam a metrópole: uma questão de currículo escolar? Elisabete Maria Garbin e Ivaine Maria Tonini

A partir de reflexões sobre educação e a centralidade da cultura em nossos tempos, este artigo é composto de insights extraídos de resultados de pesquisas inscritas no campo dos Estudos Culturais em Educação articuladas com o campo da Geografía Cultural. O foco dos estudos é dedicado aos artefatos culturais, à realização de análises culturais no campo da educação que advém do entendimento compartilhado de que a abordagem de questões cruciais da educação na contemporaneidade precisa contemplar o horizonte mais amplo da diversidade cultural, da multiplicidade de relações sociais e de ordens discursivas que produzem o que entendemos como "realidade educacional.

As últimas décadas têm sido caracterizadas como marcadas, entre outras dimensões, pela explosão do consumo, dentro de um mercado cada vez mais incentivado pela publicidade. Especificamente no caso das grandes cidades, as imagens e seus usos, são fortemente impulsionadas pela notável expansão da mídia.

Mas o que dizer sobre a centralidade da cultura? Para Hall (1997, p. 18) "as mudanças culturais globais estão criando uma rápida mudança social - mas também, quase na mesma medida, sérios deslocamentos culturais".

Como observa Du Gay (1994),

a nova mídia eletrônica não apenas possibilita a expansão das relações sociais pelo tempo e espaço, como também aprofunda a interconexão global, anulando a distância entre as pessoas e os lugares, lançando-as em um contato intenso e imediato entre si, em um "presente" perpétuo, onde o que ocorre em um lugar pode estar ocorrendo em qualquer parte [...] Isto não significa que as pessoas não tenham mais uma vida local - que não mais estejam situadas contextualmente no tempo e espaço. Significa apenas que a vida local é inerentemente deslocada — que o local não tem mais uma identidade "objetiva" fora de sua relação com o global (apud HALL, 1997, p. 18).
Ao mesmo tempo em que a comunicação via internet permite a troca instantânea de mensagens, imagens, conversas em tempo real, apagando as dificuldades advindas das distâncias de espaço, na vida presencial, a chamada globalização confirma práticas de escritas, de posturas, de presenças celebradas nas paredes, nas ruas, nos espaços das metrópoles, que se fazem através de grafites, pichações e performances corporais de toda ordem que se dão, quase que instantaneamente, em qualquer metrópole mundial.

Nas esferas acadêmicas, atualmente, há um crescente interesse por parte de educadores, para questões culturais, ou seja, o olhar parece estar focado na centralidade da cultura para se pensar o mundo.

Nossos jovens levam de alguma maneira suas culturas para as salas de aula, e a questão central está, então, em conhecer e entender esta mistura aparentemente ansiogênica de imaginários juvenis. A escola tornou-se um espaço de encontro, de trocas, de socializações. É preciso que a escola conheça mais as culturas de seus alunos, entender as novas maneiras de o aluno usar o corpo como um texto, de grafar as ruas e paredes como suas marcas de pertenças.

Claro que, atualmente, vivemos sob a égide do consumo, das imagens. Essa nova organização social nos transforma em consumidores em potencial. Consumimos mercadorias, consumimos imagens, somos interpelados por elas incessantemente. Trata-se de uma rede sutil que penetra as mais variadas instituições, dentre elas, a escola. Escola aqui, referida como aquele espaçotempo em que se dão aprendizagens de toda ordem. Escola aqui entendida como aquele espaçotempo no qual currículo não é algo natural, mas, sim, um produto cultural e, como tal, podendo sempre ser alterado.

As imagens inscritas no tecido da metrópole não podem ser vistas como simplesmente algo a mais, um aditivo na pele urbana. É preciso percebê-las como potências educativas para ler o mundo, pois há, sim, 
nelas uma cultura que as embasa e as alimenta, as quais "nos educa os olhos e muito do que temos disponível para educarmos a nós próprios e aos nossos próximos e distantes estudantes a cerca do espaço geográfico" (OLIVEIRA JR., 2009, p. 17).

Assim sendo, sob a ótica da centralidade da cultura, o objetivo deste recorte é estabelecer reflexões sobre as cenas juvenis urbanas que vivem num constante desprendimento, que, para tornarem-se notados, multiplicam sinais da sua existência de maneira visível em seus corpos performáticos, "lugarizando" espaços das metrópoles. Foram tematizados grafites, pichações e estilos juvenis que "vestem" as ruas e paredes da área central comercial e algumas de bairros residenciais da cidade de Porto Alegre/RS no período do primeiro semestre de 2010 ao primeiro semestre de 2011 e em que medida tais práticas nos fazem refletir sobre "outros" modos de "ser" e "estar" jovem nas grandes cidades, "vestidas" com as marcas de seus tempos, de seus pensamentos e de que forma tais práticas são incorporadas (ou não) pelos currículos escolares.

\section{DO ENSINO DE GEOGRAFIA, DAS CULTURAS JUVENIS ${ }^{3}$ NAS METRÓPOLES - POSSIBILIDADES, APROXIMAÇÕES E URGÊNCIAS...}

Geografia... Geografar... Geo (Terra) + graphia, do grego, significa escrita, grafia (estudo), ou seja, a geografia significa etimologicamente, o estudo da Terra. Portanto, nesse sentido, geografia passa a ser a escrita da terra, as marcas, os traços que os homens e mulheres criam na terra como uma escrita. Então geografia deixa de ser um

3 O conceito de culturas juvenis (youth cultures) está sendo usado neste trabalho como um conjunto de formas de vida e valores característicos e distintos de determinados grupos de jovens, a maneira como tais experiências são expressas coletivamente mediante a construção de seus estilos de vida distintos, localizados, fundamentalmente em seu tempo livre ou em espaços de interstício da vida profissional (FEIXA, 1999). substantivo e passa a ser um verbo. Poder-se-ia dizer que fazemos é geografar a terra? Mas o que se poderia, dizer, neste contexto, da chamada geografia cultural? Ou do interesse dos geógrafos pelos problemas culturais?

Claval (2002) assim argumenta:

o objetivo da abordagem cultural é entender a experiência dos homens no meio ambiente e social, compreender a significação que estes impõem ao meio ambiente e o sentido dado às suas vidas. A abordagem cultural integra as representações mentais e as reações subjetivas no campo da pesquisa geográfica (CLAVAL, 2002, p. 20)

De acordo com Serpa (2011, p. 24), o lugar, como fenômeno da experiência humana, "expressa e condiciona a rotina, também os confrontos, conflitos e dissonâncias, possibilitando uma leitura da vida cotidiana, com seus ritmos e contradições". Para o autor,

o espaço urbano também se produz a partir do discurso, dos conteúdos veiculados nasmaisvariadaslinguagens, expressando, a um só tempo, diferenças e similaridades, que diferenciam lugares, mas que também os relacionam com o mundo, através do rádio, do vídeo ou da internet (SERPA, 2011, p. 16).

A metrópole em seu espaço urbano tem "uma multiplicidade de estórias-até-agora", como Massey (2008, p. 158) denomina esse fenômeno, pela coexistência de uma heterogeneidade de práticas culturais contemporâneas. Como comenta a autora "tratase de um espaço como a esfera de uma simultaneidade dinâmica, constantemente desconectada por novas chegadas, constantemente esperando, por ser determinada (e, portanto, sempre indeterminada) pela construção de novas relações" (MASSEY, 2008, p. 160). Assim, pensar o espaço urbano como a esfera de uma multiplicidade de 
trajetórias através das marcas inscritas nas suas ruas, nas paredes dos prédios, nos corpos dos jovens é reter algum sentido dos múltiplos devires contemporâneos.

Segundo Garbin (2010), as revoluções culturais do nosso tempo e a emergência da chamada "cultura da mídia" - incluindo-se nela as tecnologias virtuais - em sua dimensão global, resultam numa espécie de mix cultural sustentado pelas diferenças nas condutas de jovens em suas práticas culturais que podem ser constatadas em grupos diversificados em uma mesma sala de aula. Somos interpelados incessantemente por símbolos do consumo que, ao mesmo tempo em que nos constituem dessa ou daquela maneira, acabam sendo ressignificados a todo o momento.

Nessa direção, há que se concordar que os jovens metropolitanos têm se caracterizado por suas diferentes culturas que emergem em muitos lugares. Tais culturas contribuem para os nomadismos e flutuações, bem como para a "lugarização" de determinados espaços, dentre eles, os espaços das cidades que movimentam uma espécie de rede de relações de toda ordem, seja virtual, presencial, imagética etc. Tais movimentos podem nos fazer refletir sobre "outros" modos de "ser" e "estar" jovem na contemporaneidade e nas grandes cidades, vestidas de suas marcas, de seus tempos, de seus pensamentos.

Nas palavras de Veiga-Neto (2002),

na Modernidade, o espaço e o tempo são percebidos, significados e usados como abstratos, contínuos e infinitos; além disso, a separação medieval entre um espaço interno (rígido, sensorial, de todo percorrível) e o espaço externo (fluido, desconhecido, misterioso) deu lugar a uma nova separação: entre espaço e lugar. Na Modernidade, chamamos de lugar a esse cenário onde acontecem nossas experiências concretas e imediatas; o lugar é cada vez mais entendido e vivido como um caso particular, uma projeção, de um espaço idealizado e abstrato (VEIGA NETO, 2002, p. 85).
Logo, sendo, "lugar", "lugares" e "lugarizações", ou mesmo "ilhas urbanas" referem-se a uma "porção culturalizada do espaço, isto é, um espaço ao qual se atribui (culturalmente, ou seja, por meio da prática e de marcadores culturais) determinados significados que, de certa maneira, acabam conferindo uma identidade a tal espaço" (VEIGA-NETO, 2006) Em outras palavras, estamos chamando os lugares geográficos "ocupados" pelos jovens urbanos como espaços identificados, ou seja, arriscamos assumir que seriam os lugares onde tais jovens fazem investimentos de identidade, formando comunidades. Lugares, espaços, geografias onde as identidades se constituem, negociam umas com as outras, se aproximam, se identificam, atravessando distâncias, etnias, na busca de similaridades "tribais".

No campo da geografia, no entendimento de Serpa (2011), o lugar é percebido na relação para/com o mundo pela possibilidade de nele perpassar variadas escalas e recortes. Todas operacionalizadas na produção discursiva e fixadas em plataformas de ações.

As "lugarizações", motivos de tantos nomadismos - deslocamentos constantes e ocupações "espaciais" transitórias. Ainda para VeigaNeto (2002, p. 36), "os marcadores identitários - aqueles símbolos culturais que servem para diferenciar, agrupar, classificar, ordenar inscrevem-se fundamentalmente no corpo", no corpo biológico e no corpo das cidades.

Para Canevacci (2005), as metrópoles contemporâneas são iguais às cidades nos quesitos como ruas, asfalto e mercadorias materiais. Nas metrópoles, existem ruas, asfaltos e mercadorias também e estas são mercadorias, mas são, ao mesmo tempo, sonhos. Não têm configuração, não se sabe onde começam nem onde terminam. São compostas de imagens materiais e imateriais como corpos, sons, cores, cheiros, texturas, ruídos e muito visual. Para o autor, as metrópoles são 
polifônicas, são polícromas, são comunicacionais, porque favorecem a criação de interstícios flutuantes, sem fixação, que podem durar um dia somente, os espaços são mutantes, desafiam a arquitetura e a forma.

Na Geografia, o conceito de lugar,

é, portanto, uma porta de entrada, mas também uma forma de aprofundamento das análises espaciais, a partir da definição dos espaços de conceituação pertinentes aos fenômenos que se quer explicitar, nas escalas urbana e metropolitana (CASTRO, 1995 apud SERPA, 2011, p.24).

Podemos, pelo viés da cultura, marcar a diferença em relação ao conceito lugar, numa conotação um pouco mais simbólica, menos material. Parece-nos mais interessante pensar a palavra lugar mais ligada à ocupação que se faz, ou um destino que se dá ao espaço como marcadores culturais.

Essas novas sensibilidades juvenis, que se configuram nesse século, tecem-se nos diferentes espaços sociais dos quais os jovens participam como a rua, onde se constitui uma cultura voltada para os diferentes modos de utilização do tempo livre, a casa, a escola, assim como as áreas de lazer - e nas redes de relações que aí são estabelecidas (GARBIN, 2006).

Silva (2010), em estudo sobre grafiteiros pichadores em Porto Alegre, argumenta que:

as pichações atualmente encontradas nos espaços urbanos podem ser identificadas pelos seus signos constituídos por letras quase sempre homogêneas, chamadas no Brasil de "picho reto", executado de forma rápida e, na maioria das vezes, com tinta spray (SILVA, 2010, p.27).

Canevacci (2005, p. 183) descreve esse estilo de escrita, com letras aparentemente sem compreensão, como "árabe-gótico".

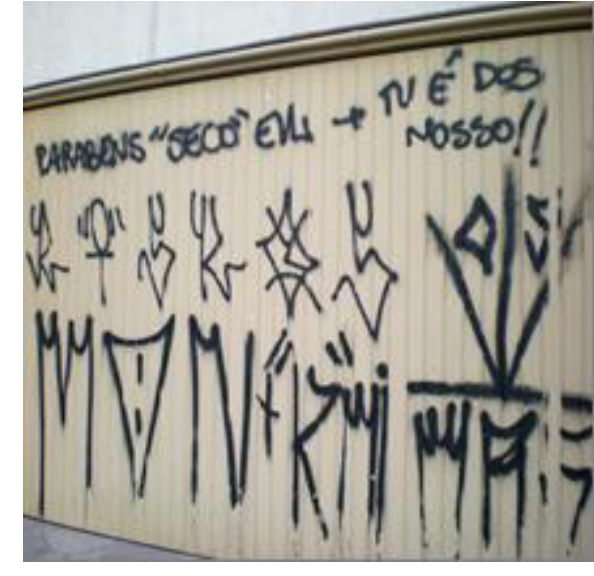

Figura 1 - Garagem "maquiada". Pichação em porta de garagem de edifício residencial em bairro nobre da cidade de Porto Alegre (RS)

Foto: Elisabete Garbin, 2010
Essas letras têm o jogo - ou o arabesco, como muito adequadamente foi definido - dos rabiscos próprios da verdadeira escrita árabe, com sua exigência quase exagerada de entrelaçamentos que constroem cifras, bordados, heras; e também a seriedade do alfabeto gótico, feito de signos convexos e côncavos, de ângulos agudos, de improvisadas acelerações, com subidas e descidas dos signos. Talvez seja devido a esta matriz obscura e misturada - simultaneamente árabe e gótica, quase o máximo da incompreensibilidade - que raramente se entenda o sentido desses grafites (CANEVACCI, 2005, p. 183).

Em outras palavras, os espaços geográficos "ocupados" por jovens urbanos caracterizam-se como "espaços identificados", ou seja, arriscamos assumir que seriam os lugares onde tais jovens fazem investimentos de identidade, formando comunidades. Lugares, espaços, geografias onde as identidades se constituem, negociam umas com as outras, se aproximam, se identificam, atravessando distâncias, etnias, na busca por similaridades "tribais".

Valenzuela (1999) argumenta que um dos fenômenos juvenis - o grafitismo, apesar de ter uma dimensão internacionalizada, adquire sentido no lazer e/ou apropriação específica realizada por jovens em diversos países, mas não faz de tais práticas algo simplificado, nem se 


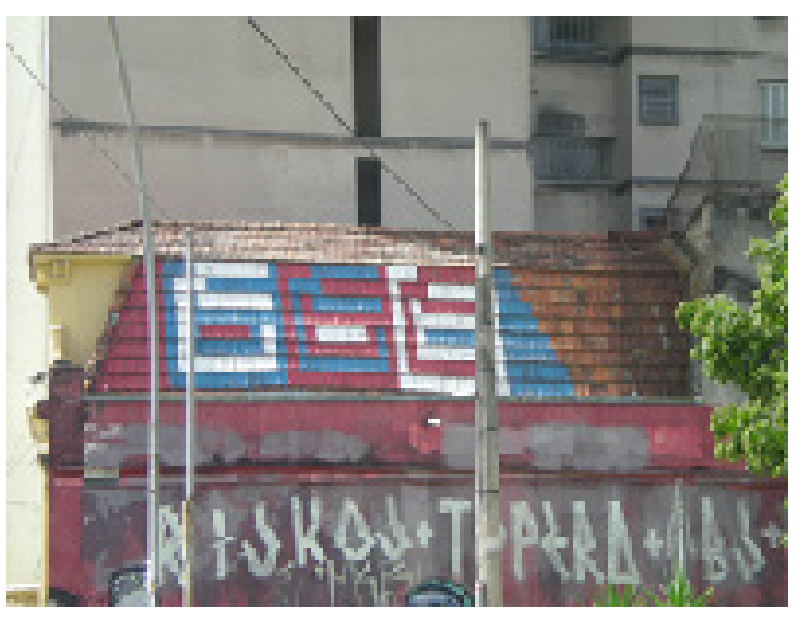

Figura 2 - Quando mais alto eu demarco a cidade, mais importância eu tenho na minha crew. Grafite temático em telhado de casa noturna e pichação lateral em área central da cidade de Porto Alegre (RS)

Foto: Elisabete Garbin, 2011 pode explicá-las através da globalização ou mesmo pelo consumo e meios massivos de comunicação.

A figura, ao lado, mostra uma sobreposição de grafite, na modalidade Tag com pichação.

É muito comum este tipo de registro nas grandes metrópoles. São as chamadas demarcações territoriais. Sob um ponto de vista antropológico, tudo é cultura num contexto urbano: ruas, asfalto, mercadorias visuais que são mercadorias e são sonhos. São corpos, visuais, sons e ruídos. É comunicacional porque favorece a criação de interstícios flutuantes, sem fixação, onde os espaços são mutantes (CANEVACCl, 2005).

\section{DA PELE DAS CIDADES - OU DOS JOVENS QUE NELA HABITAM}

Para Camevacci (2005), não há como apreender as práticas juvenis contemporâneas, tampouco rotulá-las. Desde as festas-rave, aplicação e uso de piercings, tatuagens, pichações, grafites, a cultura líquida escorre pelos desvãos da cidade. São as chamadas zonas limítrofes, os espaços vazios, os desafios panoramáticos (o corpo paisagem, a metrópole comunicacional), os atravessamentos que se tornam quase rotina para os passantes e estes se tornam parte destes cenários, muitas vezes sem nem se dar conta. Seria tais movimentos, o que se costuma chamar de nomadismos metropolitanos?

Maffesoli (2001, p.118) tematiza o nomadismo argumentando que "a figura emblemática do momento leva a uma identidade em movimento, uma identidade frágil, uma identidade que não é mais, como foi no caso da modernidade, o único fundamento sólido da existência individual e social". O nomadismo juvenil contemporâneo caracteriza-se pelo conjunto de práticas espaciais que transformam "lugares" como postos de gasolina, calçadas, parques, ruas, etc., uma mistura de pichação e bombs. Grafite em parede de prédio comercial em área central da cidade de Porto Alegre (RS)

Foto: Elisabete Garbin, 2010

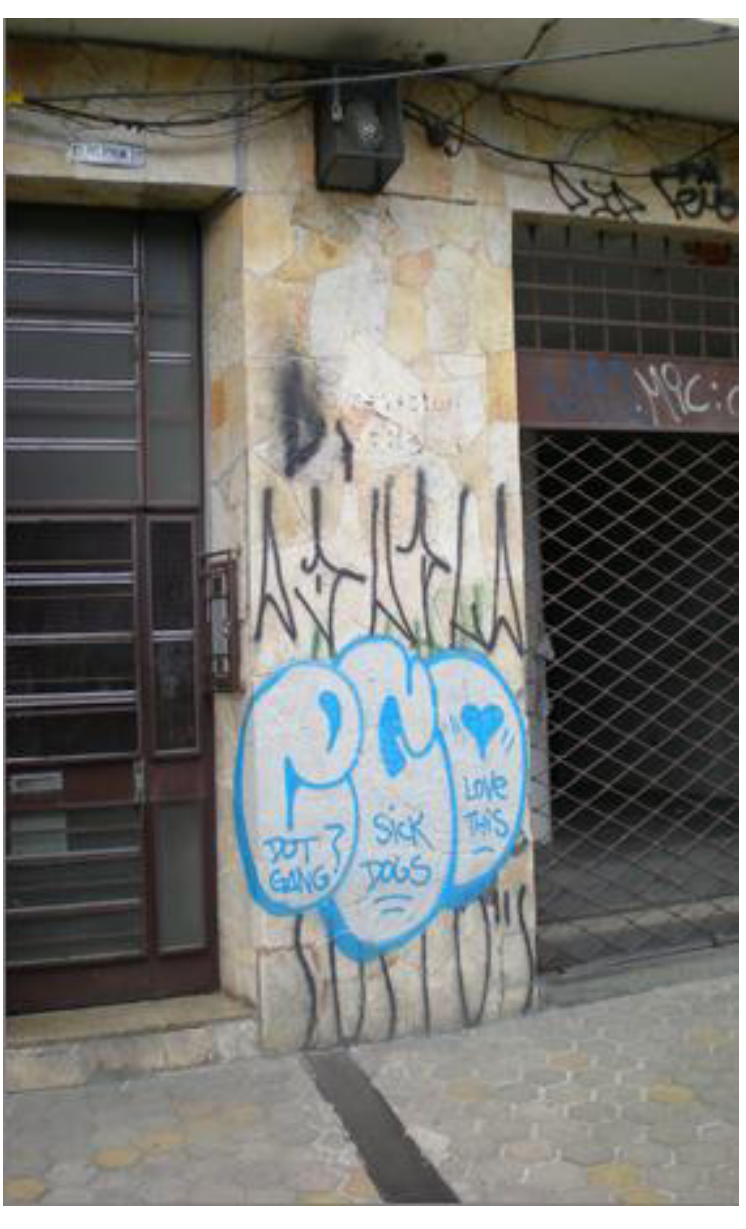


em experiências de deslocamento e não de fixação. Para Almeida e Tracy (2003, p. 41) "o nômade se distribui num espaço; ele ocupa, habita, mantém esse espaço, e aí reside seu princípio territorial". Para Garbin (2006), claro também está que uma metrópole é constituída de interstícios de zonas espaciais sem fixação, flutuantes, interligados, que podem mudar que podem durar somente um dia e podem, depois, desaparecer. Tais características de certa forma contribuem para os nomadismos e flutuações, bem como a necessidade de "lugarizar" espaços públicos por parte dos jovens urbanos.

Nessa direção, Serpa (2011) argumenta que,

lugar e mídia, ao se relacionarem, refletem e condicionam as práticas espaciais, as representações do espaço e os espaços de representação (Lefebvre, 2000), produzindo "lugares" na cidade contemporânea e abarcando diferentes dimensões escalares nesse processo (SERPA, 2011, p. 16).

Sem dúvida, os multipertencimentos dos jovens contemporâneos também ensinam modos de ser/estar, configurando nas cidades juventudes "específicas" que compartilham práticas e se identificam com estas. A tribo, o grupo, a galera, a crew, o bonde, a "bixarada", a pichação, as culturas... São espaços de inúmeras aprendizagens de jovens que se produzem dentro destas relações e tal como a educação escolarizada, outras instâncias culturais também são pedagógicas.

Os jovens possuem culturas próprias e estas precisam ser compreendidas pelos professores para que estes sejam bem-sucedidos na tarefa de educar que é um dos objetivos do estudo que enfoca as diversas formas de manifestação juvenil e suas peculiaridades, trazendo subsídios para que possa haver uma aproximação maior com o mundo dos sujeitos jovens da escola, bem como o ensino da geografia. Tais culturas contribuem para os nomadismos e flutuações,
Figura 4 - Mistura de estilos: grafite, picho reto e/ou pichações. Grafites, pichações e tags em porta e parede de casa noturna, em área central da cidade de Centro, Porto Alegre (RS)

Foto: Elisabete Garbin

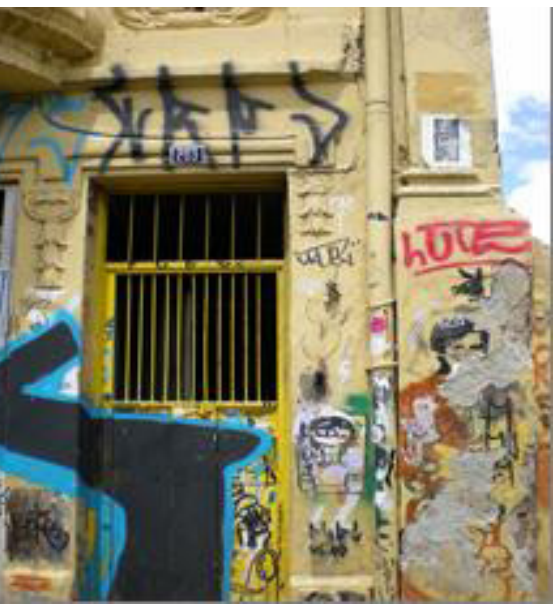

bem como para a "lugarização" de determinados espaços, dentre eles, os espaços das cidades que movimentam uma espécie de rede de relações de toda ordem, seja virtual, presencial, imagética, etc. A imagem a seguir mostra um pouco tais argumentos.

Cumpre notar, também, que o grafite é protagonizado em espaços públicos urbanos, principalmente, e sua conotação legal ou ilegal, frequentemente deriva do grupo que a realiza.

\section{E A ESCOLA? E O CURRÍCULO?}

Para Xavier (2003, p. 475), "a escola tem cada vez mais dificuldade em se apresentar como uma instituição interessante significativa". No entanto, é preciso que a escola considere os saberes e as práticas culturais de seus alunos. Como, então, essa instituição pode escutar e mobilizar esses aprendizados no seu cotidiano? Sabe-se que o cânone dos currículos escolares, em sua maioria, sustenta e reproduz saberes legitimados. Entretanto, a literatura vem mostrando que além das instituições responsáveis pela educação escolarizada, crianças e jovens constituem suas identidades através de consumos culturais, os quais produzem, interpelam, subjetivam, disciplinam, regulam e ensinam 
"Geografando" práticas juvenis que (de)marcam a metrópole: uma questão de currículo escolar? Elisabete Maria Garbin e Ivaine Maria Tonini

modos dos sujeitos de ser/estar no mundo, através de artefatos e práticas produzidas culturalmente.

Para os jovens do século XXI, dada a centralidade das tecnologias digitais nas quais foram nascidos e criados conectados à rede, a comunicação com os outros passa a ser base de quase todas as suas relações. Efetivamente, se no passado as relações de amizade se perdiam devido às distâncias e à falta de comunicações mais efetivas, nas comunidades virtuais as relações estabelecidas, ou restabelecidas à distância, acabam por criar novas atitudes e comportamentos, forjando novas identidades no que diz respeito aos sujeitos contemporâneos; e repensar a identidade em tempos de globalização é repensá-la como uma identidade multicultural que se nutre de vários repertórios, valores, discursos e forças (GARBIN, 2009a).

Os jovens trazem em suas narrativas, de qualquer ordem, o que aprendem (ou aprenderam) como a solidariedade, o humanismo, a amizade, mostrando desse modo, o (com)partilhamento de significados implicados nos processos de sociabilidade que se dão nos espaços virtuais. A escola é apenas uma das instâncias que oportuniza os processos de ensino e que poderia exercitar uma escuta mais aguçada dessas efêmeras cenas juvenis que se desenrolam também dentro dela.

É preciso negociar. É preciso (des)inventar a escola da forma como ela foi inventada, haja vista que há quem diga que os alunos são/ estão digitais e as escolas seguem analógicas, afinal, a escola tem se configurado como espaço de encontro, de conversa, de diversão, de sociabilidade, sendo, muitas vezes o "único" lugar possível para expressividades de si, nas quais a presença e o olhar do outro se torna fundamental.

É sabido que os jovens contemporâneos buscam muito mais espaços de lazer do que os adultos. Tais espaços aparecem como um lugar onde se pode desfrutar de certa autonomia, longe da autoridade adulta, dominante em outras esferas de suas vidas, como a família e a escola. É nestes espaços que os jovens podem negociar sobre seus gostos musicais, seus ídolos e suas bandas preferidas, como também construir certos espaços de autonomia para si mesmos e, neste processo, constroem identidades partilhadas. Interessante seria unir escola e vida cotidiana.

Das revoluções culturais do nosso tempo, a emergência da chamada "cultura da mídia" - incluindo-se nela as tecnologias virtuais - em sua dimensão global resulta numa espécie de mix cultural sustentado pelas diferenças nas condutas de jovens em suas práticas culturais que podem ser constatadas em grupos diversificados em uma mesma sala de aula. Somos interpelados incessantemente por símbolos do consumo que, ao mesmo tempo em que nos constituem dessa ou daquela maneira, acabam sendo ressignificados a todo o momento. Logo, se problematizarmos o conceito de juventude(s) com as lentes da cultura, pode-se ver tais juventudes como, no mínimo, comunidades de estilos, atravessadas por identidades de pertencimento, desde o look de suas vestimentas e adereços, incluindo aqui estilos musicais, comportamentos, gírias, atitudes corporais etc. Observe que alguns jovens em sua sala de aula usam um tipo de roupa que corresponde a um estilo musical que vêm consumindo neste momento, assim como outros dão seus sinais de identidade através de piercings, brincos, tatuagens e outros tipos de marcas corporais, buscando afirmar uma singularidade que já não indica uma forma de dissidência ou inconformismo social, e, sim, mais uma prática que simplesmente significa "estar na moda", "ser do grupo", e não "protesto contra o sistema capitalista", ou "protesto contra as regras hipócritas do mundo adulto". A questão central está, então, em conhecer e entender esta mistura de ânsias e imaginários juvenis. 
Assim pergunta Garbin (2010): quantas vezes neste ano, meu caro professor, você foi a uma banca de revistas para buscar por aquelas destinadas ao público juvenil? Você já experimentou convidar seus alunos a narrar em sala de aula seus conhecimentos sobre grafite, pichação, bombs etc.? Conheces os registros escritos de seus cadernos e agendas? Já percebeste que a certa altura, muito deles, nas chamadas "práticas de letramento 4 não autorizadas" - leia-se "últimas páginas dos cadernos de aula de estudantes" -, além de recados para colegas, lembretes, signos, seus alunos registram seus próprios nomes pela técnica (de letra) chamada de bomb? Conheces as letras de algumas dessas técnicas de escrita?

Por tal, é preciso que saibamos que os processos cotidianos de fragmentação somados ao poder da cultura da massa, inscrita em códigos e estilos, gestos e performances, têm nas cenas juvenis um terreno próprio para a formação de identidades. Assim sendo, todas as interpelações culturais que absorvemos em nossa vida, em nosso ritmo, em nossos corpos é uma experiência de identidade - não algo que se adquira de forma acabada e pontual, mas, sim, um processo gradual. Dessa forma, pode-se pensar que jovens não nascem grafiteiros e, sim, tornam-se, são subjetivados de alguma forma como grafiteiros e não por toda a vida, mas por períodos dela. Os discursos e práticas dos jovens demonstram o hibridismo, o "tingimento" identitário que os interpela. É uma espécie de declaração: eu sou (ev estou) eu grafito,

4 Por práticas de letramento entendemos, juntamente com Soares (2002; 2003), como "a indissociabilidade entre o letramento e a alfabetização e a indissociabilidade entre as dimensões individual e social do letramento. [...] Letramento não é pura e simplesmente um conjunto de habilidades individuais; é o conjunto de práticas sociais ligadas à leitura e à escrita em que os indivíduos se envolvem em seu contexto social" (2002, p. 72). Assim, o letramento social que envolve as diferentes dimensões do letramento individual define-se como "[...] o que as pessoas fazem com as habilidades de leitura e de escrita, em um contexto específico, e como essas habilidades se relacionam com as necessidades, valores e práticas sociais" (SOARES, 2003, p. 72). Nesse sentido, entendemos que a prática de alunos de escrever bombs e tags nos cadernos escolares pode ser considerada uma prática de letramento. eu picho, eu ocupo o que eu ouço, eu penso, ou eu penso que sou neste momento, neste lugar, neste contexto.

McRobbie (1995), quando se refere ao processo de aquisição de identidade no terreno dos Estudos Culturais, assinala que

por um lado ele é fluido, nunca completamente assegurado e está continuamente sendo refeito [...] por outro lado, ele só existe em relação ao que não é, às outras identidades que são seu "outro"; [...] a identidade, portanto, está fundada na identidade social, em grupos sociais ou populações com algum sentido de uma história e de uma experiência partilhada" (McROBBIE, 1995, p.58-59).

Nessa direção, Ewen (1991) argumenta que na contemporaneidade, vivemos sob a égide de uma política do estilo, ou seja, que a partir do "estilo", construímos marcas de distinção, de identidade e um lugar no mundo. Já para Carmo (2001, p. 203) "o grupo e o indivíduo passam a ser reconhecidos pelos adereços e vestimentas que usam, e o estilo torna-se importante expressão da identidade do grupo e dos ideais por ele adotados".

Para Xavier (2010, p. 94) "a escola precisa se vista como um espaço para aprender e aprender a viver. É necessário redescobrir o vínculo entre a sala de aula e a vida fora da escola para a qualificação de ambas". Em vista disso, conforme Garbin (200gb),

podemos entender as juventudes do século XXI em seus espaços e tempos escolares ancorados em Bill Green e Chris Bigum (1995), que argumentam que está surgindo "um novo tipo de estudante, com novas necessidades e novas capacidades" (p. 209). Concluise que as tribos juvenis são produzidas "na convergência dos discursos contemporâneos sobre a juventude, sobre a cultura da mídia e sobre o pós-modernismo" (p.209). A partir dessas premissas, constata-se que ser diferente de alguns sendo igual a outros é a máxima do individualismo contemporâneo. Todavia, nota-se um movimento incessante e espiralado que 
inclui uniformização, identificação e pluralização. Movimento esse que não cessa, portanto, na uniformização, tendo em vista que identificar a formação de tribos não significa pressupor a existência de um grupo fechado em si mesmo, mas, pelo contrário, é pressupor os infindáveis processos de identificação que não cessam de modificar os modos dos sujeitos "serem", se posicionarem, produzindo novas culturas (GARBIN, 200gb, p. 17).

Certo é que a juventude contemporânea tem se caracterizado por suas diferentes culturas, que afloram em muitos lugares, ao mesmo tempo, como a da geração zapping, da geração digital, das características de nomadismos, da linguagem do "tipo assim", da "parada animal", enfim, urge que nos percebamos - e também os nossos alunos e alunas - como sujeitos de uma condição cultural que através de inúmeros investimentos nos modifica, transforma e constitui diferentes maneiras de ser e estar no mundo.

Não fiquemos no passado, não julguemos e não condenemos preliminarmente, não façamos relações de causa e efeito entre determinadas manifestações juvenis e traços de caráter para não repetirmos os intermináveis (e cada vez mais aprofundados) choques de geração, sob pena de nos transformarmos em "alienígenas" diante de nossos alunos e alunas[!].

\section{REFERÊNCIAS}

ALMEIDA, Maria Isabel Mendes de, TRACY, Kátia Maria de Almeida. Noites nômades - espaços e subjetividades nas culturas jovens contemporâneas. Rio de Janeiro: Rocco, 2003.

CANEVACCl, Massimo. Culturas extremas: mutações juvenis nos corpos das metrópoles. Tradução de Alba Olmi. Rio de Janeiro: DP\&A, 2005 .
CARMO, Paulo Sérgio do. Culturas da rebeldia - a juventude em questão. São Paulo: SENAC, 2001.

CASTRO, Iná Elias de. O problema da escala. In: CASTRO, Iná Elias de; GOMES, Paulo César da Costa; COOREA, Roberto Lobato (Orgs.). Geografia: conceitos e temas. Rio de Janeiro: Bertrand, 1995.

CLAVAL, Paul. A volta do cultural na geografia. Revista Mercator, $\mathrm{n}$. 01, p.19-28, 2002.

EWEN, Stuart. Todas las imágenes del consumismo - la política del estilo en la cultura contemporánea. México: Editorial Grijalbo, 1991.

FEIXA, Carles. De Jóvenes, Bandas y Tribus. Antropologia de la juventud. Barcelona: Editorial Ariel, 1999.

GARBIN, Elisabete Maria. Cenas Juvenis em Porto Alegre: "lugarizações", nomadismos e estilos como marcas identitárias. In: SOMMER, Luis Henrique e BUJES, Maria Isabel Edelweiss (Orgs.). Educação e cultura contemporânea: articulações, provocações e transgressões em novas paisagens. Canoas: Editora da ULBRA, 2006. p.199-215

Conectados por um fio: alguns apontamentos sobre internet, culturas juvenis contemporâneas e escola. In: Juventude e escolarização: os sentidos do Ensino Médio Ano XIX Boletim 18 Novembro/2009a. Disponível em: < http://tvbrasil.org.br/fotos/salto/ series/11100718-JuveEscoladoEM.pdf>

Diferentes de alguns, iguais a outros! As culturas juvenis invadem a escola. In: KOBOLDT, Márcia Cavalcante e SOUZA, Rui Antônio. Culturas Juvenis dinamizando a escola. Porto Alegre: EDIPUC/RS - Mundo Jovem - 2009b, p. 11-18.

Efemeridades e liquidez nas práticas culturais juvenis. Revista Pátio - Ensino Médio, série Culturas Juvenis. Ano II - junho/agosto 2010. n.5, Porto Alegre: ARTMED, 2010, p.10-13.

HALL, Stuart. A Centralidade da Cultura: Notas sobre as revoluções culturais do nosso tempo. Revista Educação \& Realidade, v. 22, n. 2, 1997, p. 15-46. 
MAFFESOLI, Michel. Sobre o nomadismo - vagabundagens pósmodernas. Rio de Janeiro: Record, 2001.

MASSEY, Doreen. Pelo espaço. Uma nova política da espacialidade. Rio de Janeiro: Bertrand, 2008.

McROBBIE, Angela. Pós-marxismo e estudos culturais. In: SILVA, Tomáz Tadeu (Org.). Alienígenas na sala de aula, Petrópolis: Vozes, 1995, p.39-6o.

OLIVEIRA JR., Wenceslao Machado de. A educação pels imagens e suas geografias. In: Dossiê - A educação pelas imagens e suas geografias. Pro-Posições, Campinas, v.20, n.3 (60), set./dez., 2009.

SERPA, Angelo. Lugar e mídia. São Paulo: Contexto, 2011.

SILVA, Eloenes Lima da. A gente chega e se apropria do espaço! Graffiti e pichações demarcando espaços urbanos em Porto Alegre. Dissertação (Mestrado em Educação) - Programa de Pós-Graduação em Educação. Faculdade de Educação. Universidade Federal do Rio Grande do Sul, 2010.

SOARES, Magda. Letramento: um tema em três gêneros. 2 ed. Belo Horizonte: Autentica, 2002.
Letramento e escolarização. In: RIBEIRO, Vera Masagão (Org.). Letramento no Brasil. Global: São Paulo, 2003.

VALENZUELA, José Manuel Arce. Vida de barro duro: cultura popular juvenil e grafite. Trad. Heloisa B. S. Rocha. Rio de Janeiro: Editora da UFRJ, 1999.

VEIGA-NETO, Alfredo José da. Informações sobre conceitos de lugar/espaço/território. [Mensagem pessoal] Mensagem recebida por<emgarbin@terra.com.br> em 21 de julho de 2006.

Alfredo José da. Espaço e Currículo. In: LOPES, Alice Casimiro e LOPES, Elizabeth F. (Orgs). Disciplina e integração curricular: História e Políticas. Rio de Janeiro: DP\&A, 2002, p. 201-220.

XAVIER, Maria Luisa Merino. Os incluídos na escola: o disciplinamento nos processos emancipatórios. Porto Alegre: UFRGS, 2003. Tese (Doutorado em Educação)-Programa de Pós-Graduação em Educação, Faculdade de Educação, Universidade Federal do Rio Grande do Sul, Porto Alegre, 2003

Escola contemporânea: o desafio do enfrentamento de novos papéis, funções e compromissos. In: BUJES, Maria Isabel Edelweiss e BONIN, lara Tatiana (Orgs.) Pedagogias sem Fronteiras. Canoas: Ed. Ulbra, 2010, p. 93-104.

Submetido em Janeiro de 2012. Revisado em Abril de 2012. Aceito em Agosto de 2012. 